\title{
Percurso do estudante de medicina na formação da identidade profissional desde o curso médio até o meio do curso
}

\author{
The medicine undergraduate's path to construct \\ a professional identity from the middle course to \\ the middle of the course
}

\section{Isabella de Farias Costa Fernandes ${ }^{1}$ (D) leda Maria Barbosa Aleluia² (1)}

\begin{abstract}
${ }^{1}$ Autora para correspondência. Escola Bahiana de Medicina e Saúde Pública (Salvador). Bahia, Brasil. bella_fernandes2@hotmail.com
\end{abstract} ²Escola Bahiana de Medicina e Saúde Pública (Salvador). Bahia, Brasil. iedaleluia@bahiana.edu.br

RESUMO | INTRODUÇÃO: Em seu percurso, os estudantes encontram nos primeiros anos da faculdade, a influência principalmente das disciplinas humanísticas e experiência com professores. Até o segundo ano, o estudante do ciclo básico passa por frustrações diante das expectativas criadas anteriormente ao ingresso da faculdade. Eles constroem identidades profissionais a partir dos discursos concorrentes de diversidade e padronização; usam e negociam esses discursos de maneira diferente e experimentam o processo de construção de maneira diferente, dependendo de suas identidades sociais únicas; e, como resultado, eles constroem diferentes tipos de identidades profissionais. OBJETIVO: Investigar o percurso do estudante na formação da identidade profissional desde curso médio até o meio do curso de medicina, em uma instituição privada de Salvador/BA. METODOLOGIA: Estudo de corte transversal, observacional, de abordagem quantitativa/qualitativa. Alunos no $5^{\circ}$ e $6^{\circ}$ semestres de medicina, de 2019.1. Questionário aplicado presencialmente. Análise estatística descritiva, programa IBM SPSS Statistics20.0. As variáveis numéricas foram analisadas seguindo as tendências central e de dispersão. A análise qualitativa pela análise do conteúdo. Aprovado no CEP com o CAAE 03547118.6.0000.5544. RESULTADOS: Foram respondidos197 questionários. Média de idade de $21,86+/-2,3$; são do sexo feminino 111 (56,3\%) estudantes; 88 $(44,7 \%)$ católicos; $99(50,3 \%)$ do $5^{\circ}$ semestre e $98(49,7 \%)$ do $6^{\circ}$ semestre; todos são solteiros, 197 (100\%); 130 (69\%) moram com os pais; 84 (93,4\%) sem formação profissional prévia. Tempo médio de curso pré-vestibular de 1,21 anos (DP +/- 1,03); $181(91,9 \%)$ participam de alguma atividade extracurricular; $137(69,4 \%)$ responderam vocação como motivação para fazer medicina; 190 (96,4\%) participantes responderam que houve mudança na maneira de pensar e agir diante do paciente e de questões humanísticas; $161(81,7 \%)$ responderam que as expectativas foram atendidas pelo curso; $120(60,9 \%)$ responderam não se sentem desmotivados, culpados ou com vergonha quando falham durante a prática clínica. $190(96,4 \%)$ percebem a influência do professor na sua formação; 186 (94,4\%) percebem conteúdo humanístico no currículo; 99 (50,3\%) concordaram fortemente que há competitividade dentro do curso; 94 (47,7\%) concordam fortemente e $72(36,5 \%)$ concordam que se sentem "mais médico" após o início das práticas clínicas/ hospitalares. Concordaram fortemente $34(17,3 \%), 35(17,8 \%)$ concordaram e $73(37,1 \%)$ concordaram em parte que sentem usar o paciente como objeto; $89(45,2 \%)$ concordam fortemente e $80(40,6 \%)$ concordam que a escolha por uma especialidade pode ser influenciada por um professor/médico/mentor; $43(21,8 \%)$ dos participantes concordaram fortemente que há influencia no modo de se comportar e vestir, 69 (35\%) concordaram com a afirmativa. CONCLUSÃO: É possível inferir que os estudantes entram no curso muito jovens e sem alguma experiência no ambiente de ensino superior. A vocação como motivação seguida do desejo do conhecimento e da influência de pais e família, apontam para o lado humanístico na escolha do curso, apontando também as influências do currículo oculto como o desejo da família e a presença de um familiar exercendo a profissão. Existe satisfação com o ingresso no curso, com as experiências vividas e como elas transformaram de uma maneira positiva os estudantes: a proximidade com o paciente, o currículo, o professor.
ABSTRACT | INTRODUCTION: Students selected during their early years have a strong influence on humanitarian disciplines and teacher experience. By the second year, the undergraduate student experiences impressions from previous expectations before entering college. They build professional identities from competing discourses of diversity and standardization; use and negotiate these discourses differently and experience the building process differently, depending on your unique social identities; and as a result, they build different types of professional identities. OBJECTIVE: To investigate or track students in professional identity formation from high school to medical school, in a private institution in Salvador / BA. METHODOLOGY: Cross-sectional observational study with a quantitative / qualitative approach. Students in the 5th and 6th semesters of medicine, 2019.1. Questionnaire via email, or in person. Descriptive statistical analysis, IBM SPSS Statistics20.0 program. Numerical variables were analyzed following central and dispersion trends. A qualitative analysis by content analysis. Study was cleared by the local ethics committee under approval number 03547118.6.0000.5544. RESULTS: 197 students answered the questionnaire. Mean age $21.86+/-2.3$; 111 (56.3\%) female; 88 (44.7\%) Catholics; 99 (50.3\%) of the 5th semester and $98(49.7 \%)$ of the 6th semester. $197(100 \%)$ single and $130(69 \%)$ live with their parents. $184(93.4 \%)$ without previous vocational training. Mean pre-vestibular course time of 1.21 years (SD +/- 1.03). 181 (91.9\%) participate in some extracurricular activity. 137 (69.4\%) answered vocation as motivation to do medicine. 190 (96.4\%) participants answered that there was a change in the way of thinking and acting in front of the patient and humanistic issues. $161(81.7 \%)$ answered that the expectations were met by the course. $120(60.9 \%)$ respondents do not feel unmotivated, guilty or ashamed when they fail during clinical practice. 190 (96.4\%) perceive the influence of teachers in their education. $186(94.4 \%)$ perceive humanistic content in the curriculum. 99 (50.3\%) strongly agreed that there is competitiveness within the course. 94 (47.7\%) strongly agree and 72 (36.5\%) agree that they feel "more medical" after the start of clinical / hospital practices. $34(17.3 \%)$ strongly agreed, $35(17.8 \%)$ agreed and $73(37.1 \%)$ agreed in part that they feel using the patient as an object. 89 (45.2\%) strongly agree and $80(40.6 \%)$ agree that the choice for a specialty may be influenced by a teacher / physician / mentor. $43(21.8 \%)$ of the participants strongly agreed that there is influence on the way they behave and dress, 69 (35\%) agreed with the statement. CONCLUSION: It is possible to infer that students enter the course very young and without any experience in the higher education environment. The vocation as motivation followed by the desire for knowledge and the influence of parents and family, point to the humanistic side in choosing the course, also pointing to the influences of the hidden curriculum such as the desire of the family and the presence of a family member practicing the profession. There is satisfaction with entering the course, with their experiences and how they have positively transformed students: the proximity to the patient, the curriculum, the teacher.

KEYWORDS: Medical education. Professional identity. Medicine student. Curriculum
PALAVRAS-CHAVE: Educação médica. Identidade profissional. Estudante de medicina. Currículo. 


\section{Introdução}

"[...] Manterei a minha vida e a minha arte com pureza e santidade; qualquer que seja a casa em que penetre, entrarei nela para beneficiar o doente; evitarei qualquer ato voluntário de maldade ou corrupção [...]"1‥1. Este é um dos trechos do juramento de Hipócrates, pai da medicina, clamado nas formaturas do curso ainda hoje. O trecho reflete uma visão da sociedade sobre o médico e o sacerdócio da profissão. No entanto, implica ao profissional atributos que por vezes não possuem, mas que podem ser adquiridos ou não durante o decorrer do curso. Permeando a formação científica do estudante, então, tem-se também a formação da identidade profissional, que inclui tanto o currículo formal quanto informal, influências extracurriculares. Vê-se nos primeiros anos de curso a evolução, aperfeiçoamento e a padronização da ideia proposta por Hipócrates aos estudantes. Dessa forma, é de grande importância a vivência dos primeiros anos para a formação da identidade, pois trata-se da base do currículo formal e informal que deve ser aprendido para que o juramento seja o mais próximo da realidade ${ }^{1}$.

Segundo Zimmerman (Jorge Neto AD. 2013, p. 267), define-se identidade como "a propriedade que se tem de manter-se o mesmo, independente das pressões". São as características que o indivíduo traz consigo ao longo da vida, que fazem parte da personalidade, afetos, cultura, experiências e conhecimentos adquiridos ${ }^{2}$. A identidade profissional é, portanto, a articulação do subjetivo e o objetivo visto durante o curso e que compõem particularidades assimiladas em uma ideologia partilhada pelo grupo profissional.

Não obstante, essa ideologia traz consigo a visão do sacerdócio médico no qual este deve apresentar características como ser inteligente, estudioso, sensível, seguro, inspirar confiança, saber dosar trabalho e lazer, estar sempre disponível, ser competente tecnicamente e saber compreender o paciente ${ }^{1}$. Estes atributos por vezes vêm com os estudantes muito antes da entrada no curso, e é a partir da presença deles que é feita a escolha pela profissão. No entanto, pode-se também desenvolvê-los na faculdade com o curso e disciplinas humanísticas, pela experiência com professores que as detenham, pela influência de colegas e pelas próprias experiências vividas ${ }^{3}$.
Em seu percurso, os estudantes encontram nos primeiros anos a influência principalmente das disciplinas humanísticas e experiência com professores. Até o segundo ano, o estudante do ciclo básico passa por frustrações diante das expectativas criadas anteriormente ao ingresso da faculdade. Eles constroem identidades profissionais a partir dos discursos concorrentes de diversidade e padronização; usam e negociam esses discursos de maneira diferente e experimentam o processo de construção de maneira diferente, dependendo de suas identidades sociais únicas; e, como resultado, eles constroem diferentes tipos de identidades profissionais ${ }^{1}$.

Os discursos, práticas, normas e expectativas da escola médica e da profissão são as ferramentas que os estudantes de medicina usam para construir suas identidades. Embora os discursos de diversidade e padronização sejam de modo algum as únicas ferramentas que os alunos são expostos, dado sua entrada recente na educação médica, pode-se esperar que esses discursos sejam recursos significativos dentro do repertório sociocultural disponível ${ }^{3}$. Assim, os discursos de padronização e diversidade transmitem mensagens e sugestões importantes e poderosas aos alunos sobre o que significa ser um médico e como eles devem se tornar um.

No Brasil não foram encontrados estudos sobre a formação profissional do estudante de medicina na graduação, principalmente sobre o percurso do estudante desde antes de sua entrada até o meio do curso. Este estudo abrange as influências da escoIha do curso e da graduação na sua formação, quais eram as expectativas diante da imersão na medicina, o que mudou até o meio do curso e como se identifica com ele. Para isto, foi realizada uma análise destes aspectos com estudantes de medicina na cidade de Salvador-Bahia.

\section{Revisão de literatura}

A identidade profissional é entendida no âmbito da educação médica por diversos autores como a essência do indivíduo diante de pressões e de diversas situações compreendendo o conhecimento do indivíduo, afetos, experiências, como se comporta e como se comunica². A definição de identidade do Oxford English Dictionary (apud Cruess et al. 2014, 
p. 1447) é "um conjunto de características ou uma descrição que distingue uma pessoa ou coisa de outros." ${ }^{\prime 4}$. Para o médico, é a representação de si, alcançada em estágios ao longo do tempo em que as características, valores e normas da profissão médica são internalizadas, resultando pensar, agir e se sentir como um médico 4 .

A formação da identidade profissional (PIF) é um um processo de desenvolvimento adaptativo que acontece simultaneamente em dois níveis de acordo com Jarvis-Selinger et al. (apud Cruess et al. 2014, p. 1448): "(1) ao nível do indivíduo, que envolve o desenvolvimento psicológico da pessoa e (2) no nível coletivo, que envolve a socialização da pessoa em papéis apropriados e formas de participação no trabalho da comunidade $^{\prime \prime}$. O desenvolvimento psicológico dá-se através do conjunto de valores, habilidades, conhecimentos que já faziam parte da sua identidade, currículo oculto, e que vão sofrer aprimoramento durante o percurso universitário, culminando em atributos, expressões e comportamentos que o inserem dentro de uma nova comunidade social .

A nível coletivo, a identidade será pautada nas experiências pessoais e interações em ambientes de aprendizagem como salas de aula, ambulatórios, hospitais, comunidades e o sistema único de saúde. O que se espera como resultado da PIF é o profissionalismo. De acordo com uma revisão sistemática de Wilkinson et al. (apud Findyartini, Sudarsono, 2018, p. 1), o profissionalismo é composto por cinco aspectoschave: confiabilidade; adesão aos princípios éticos; interações efetivas com pacientes, seus familiares e outros significativos; interações efetivas dentro do sistema de saúde; e um compromisso de melhorar a competência de si mesmo, dos outros e do sistema de saúde ${ }^{5}$. Irby et al. (apud Findyartini, Sudarsono, 2018 , p. 2), argumentam que o profissionalismo deve ser considerado como um conjunto de valores e atributos éticos (profissionalismo baseado na virtude), um conjunto de comportamentos (profissionalismo baseado no comportamento) ou um método para a formação da identidade pessoal; estas três visões são baseadas em diferentes construtos que podem aprofundar a compreensão do profissionalismo ${ }^{5}$.

Como o PIF é um processo de desenvolvimento complexo, não-linear, influenciado por características pessoais, experiências e fatores socioculturais, o seu começo se dá a partir da escolha pelo curso.
As motivações que levariam jovens adolescentes a essa opção profissional pertencem a dois níveis: conscientes e inconscientes. Do ponto de vista das motivações conscientes estão o desejo de compreender, de ver, o desejo de contato, o prestígio social, o prestígio do saber, o alívio prestado aos que sofrem, a atração pelo dinheiro, a necessidade de ser útil, a atração pela responsabilidade ou pela reparação, o desejo de uma profissão liberal e a necessidade de segurança. (Ramos, 2002, p.109)

Como inconsciente, tem-se o desejo de ver e saber sobre sexo e morte, temas considerados tabus e que a profissão permite transgredir; desejo de reparar e de poder ${ }^{1}$.

No início do curso, o estudante começa o processo de transição entre o ensino médio e o ensino superior que nos últimos anos vem trabalhando com uma proposta mais dinâmica de ensino ${ }^{1}$. O Problem Based Learning ( $\mathrm{PBL}$ ) foi o método implantado que permitiu essa dinamicidade a partir do momento que coloca o estudante como responsável pelo seu aprendizado e membro de um pequeno grupo ${ }^{1}$. No terceiro ano, metade do curso, os alunos começam o contato com a clínica e a partir daí vão construir experiências com a prática médica. Para o "terceiranista", cabe apenas examinar quem já foi examinado, fazer a anamnese de quem já tem diagnóstico, já está internado e em tratamento. Sente que seu trabalho não serve ao paciente e, muitas vezes, se ressente de usá-lo como objeto. Até então nada lhe ensinaram sobre o sentir, o ser da pessoa doente ${ }^{1}$. A "bagunça" da prática clínica está no centro do entendimento do "devir" pelo estudante.6 Para Gracey (apud Wald HS. et al. 2018, p. 7), a proposta é engajar os alunos na reflexão crítica orientada sobre experiências complexas dentro de um clima humanístico de aprendizagem como uma maneira valiosa de cultivar profissionais reflexivos e resilientes com mentes e corações "preparados" para os inevitáveis desafios da assistência à saúde prática, idealmente preservando o humanismo na medicina ${ }^{6}$.

O desequilíbrio desencadeado pela transição do estudante de graduação para o estudante de medicina resultou em uma mudança na forma como os alunos se percebiam, antes com uma identidade multifacetada e agora com uma identidade singular ${ }^{7}$. Essa mudança pode representar uma perda não apenas do eu, mas das atividades e relacionamentos que os alunos desfrutaram anteriormente ${ }^{7}$. Os alunos passam a funcionar a partir de uma identidade singular como 
uma resposta prática às novas demandas de se tornar um médico. Ocorre, portanto, uma padronização do estudante à profissão.

Não fazendo mais parte do mundo leigo dos pacientes, mas ainda à margem da profissão médica, gerações de estudantes de medicina têm sido desafiadas a entender quem são no contexto de sua formação e quem elas serão no contexto da profissão 3 . Dentro do processo PIF há três fatores que convergem e dificultam-no, são eles a diversidade das aulas de medicina; a presença de dois discursos diferentes, um que promove a diversidade e outro que enfatiza a padronização e a uniformidade; e a tensão entre os discursos sem uma assistência por parte dos mentores. Apesar de todos os obstáculos e mudanças históricas e culturais observadas durante a evolução do conhecimento médico e da educação médica, é fácil reconhecer uma característica comum que permanece também como pilar da educação médica: o papel de um mentor / mestre cujo exemplo deve ser seguido. Essa "referência" sempre foi um modelo para a transmissão do conhecimento médico, incluindo suas diferentes dimensões, como aspectos técnicos, responsabilidade social e comportamento humanitário ${ }^{8}$.

Dessa forma, o foco pedagógico deve estar presente principalmente no período de aprendizagem, tanto por experiência pessoal quanto pela experiência e conhecimento transmitido pelo mentor.

Existe um "produto além da atividade", ou seja, o aluno adquire uma nova habilidade ou expande a base de dados. E há também um produto "inerente à atividade", ou seja, o desenvolvimento do personagem do aprendiz. As condições favoráveis a tal amadurecimento requerem um espaço relacional entre professor e aluno, caracterizado por apoio emocional e reflexão guiada implacável. O relacionamento deve ser estimulante e não julgador, e o aprendiz deve ser encorajado a desafiar as verdades recebidas. (Boudreau, Fuks, 2014, p.14)

Diante dessa relação professor-aluno, a compreensão e reconhecimento das emoções vão proporcionar a modulação de conceitos do aluno sobre si, suas crenças e sobre a profissão escolhida. Trata-se de um treinamento de resiliência emocional, no qual a prática junto com seus erros e acertos e o acompanhamento adequado do mentor o estimulam a continuar e a se aprimorar. O resultado do "treinamento de resiliência emocional" seria alunos e professores que capazes de reconhecer emoções autoconscientes prejudiciais (por exemplo, vergonha e culpa) quando elas ocorrem, envolvam-se com elas de uma maneira autêntica e aberta, e atentamente as transforma em respostas emocionais mais construtivas (por exemplo, aprendizado) ${ }^{10}$.

Não obstante, a entrada dos estudantes no curso vem acompanhada de identidades pré-existentes formadas pelo currículo oculto. Assim, a maneira como lidam com experiências, principalmente no terceiro ano com a iniciação da prática clínica difere, apesar do treinamento de resiliência que possivelmente recebem pela equipe pedagógica. O currículo oculto fará com que o estudante se olhe diante da profissão de acordo ao que mais se assemelha à sua essência, consolidando sua identidade. De forma concomitante, porém, coadjuvante, o currículo formal é percebido pela modulação do estudante ao profissionalismo requerido pela profissão, e que também contribui para, de alguma forma, o equilíbrio cognitivo e afetivo ${ }^{1,3,7,9}$.

\section{Objetivos}

\section{Objetivo geral}

- Investigar a formação da identidade profissional durante o percurso do estudante desde curso médio até o momento do meio do curso de medicina.

\section{Objetivos específicos}

- Identificar e analisar as influências que levaram o estudante de medicina a escolher o curso;

- Identificar quais eram as expectativas antes de iniciar o curso;

- Identificar as expectativas no início da formação e verificar a ocorrência de mudanças nesse momento.

- Mapear os fatores do currículo formal que influenciaram o estudante de medicina durante o curso até o momento atual, meio do curso. 
- Entender como os estudantes de medicina percebem a formação de identidade na faculdade e na futura profissão.

\section{Métodos}

\section{Desenho do estudo}

Trata-se de um estudo de corte transversal, de natureza observacional com abordagem quantitativa e qualitativa.

\section{Delineamento}

A pesquisa foi realizada com alunos cursando os $5^{\circ}$ e $6^{\circ}$ semestres do curso de Medicina. A abordagem com os alunos foi feita presencialmente, convidando-os a responder o questionário em Apêndice $A$, juntamente com o Termo de Consentimento Livre e Esclarecido (TCLE) (Apêndice B). A abordagem presencial se deu por meio de convite aos estudantes, em horário de aula, com o devido consentimento do professor presente, e entrega do questionário e TCLE ao final da mesma.

O trabalho foi realizado através da aplicação de um questionário com questões abertas e fechadas contemplando os objetivos do estudo de acordo às referências encontradas na literatura. A questão aberta foi construída na busca de breves narrativas sobre o $1^{\circ}, 2^{\circ}$ e $3^{\circ}$ ano do ciclo básico.

\section{População do estudo}

A população do estudo envolveu 197 alunos cursando o $3^{\circ}$ de Medicina durante o período de 2019.1 que participaram de uma pesquisa censitária.

Os critérios de inclusão da pesquisa foram estudantes de medicina, maiores de 18 anos, cursando o $5^{\circ}$ e $6^{\circ}$ semestres, que concordaram com o TCLE e responderem ao menos $75 \%$ do questionário.

\section{Metodologia da coleta de dados}

A pesquisa foi realizada por meio da aplicação de um questionário contendo informações sócio demográficas dos estudantes e questões relacionadas às influências desde a escolha do curso até o momento presente da graduação, expectativas diante do curso, como se identificam e se sentem diante da graduação e da futura profissão e sobre o currículo. O questionário foi aplicado via presencial, não havendo necessidade de ser enviado via email.

O questionário estruturado foi aplicado pelo pesquisador durante o período letivo nos intervalos das atividades acadêmicas utilizando o ambiente da EBMSP, em horário e sala previamente marcados, tendo duração máxima de 30 minutos, após o convite ter sido feito aos estudantes, em horário de aula, com o devido consentimento do professor presente.

\section{Variáveis de investigação}

As variáveis do estudo foram sexo, semestre, idade, estado civil, outra formação prévia, situação de moradia (pais/sozinho/amigos/parentes), realização de curso pré-vestibular e por quanto tempo, forma de escolha do curso e aspectos relacionados as práticas da graduação em medicina, expectativas quanto a profissão e aspectos pessoais que influenciam na formação da identidade profissional.

\section{Processamento e análise dos dados}

A análise quantitativa foi descritiva, realizada pelo programa IBM SPSS Statistics20.0. As variáveis numéricas foram analisadas seguindo as tendências central e de dispersão das variáveis conforme apropriado (variável contínua ou categórica) para a caracterização da casuística e apresentação dos resultados.

A análise qualitativa foi realizada através da metodologia de análise do conteúdo de Bardin ${ }^{16}$, sendo as respostas dos alunos agrupadas por ano do curso e categorizadas. 
O respectivo estudo foi submetido e aprovado, CAAE 03547118.6.0000.5544, pelo Comitê de Ética em Pesquisa (CEP). Os aspectos éticos foram embasados através resolução $N^{\circ}$ 466/12 do Conselho Nacional de Saúde (BRASIL, 2014), que regulamenta pesquisas com envolvimento direto ou indireto de seres humanos. Toda pesquisa que envolve seres humanos tem riscos para os participantes.

Os riscos da pesquisa foram relacionados com os resultados e a obtenção de dados que pudessem ser insuficientes ou que não demonstrassem claramente as principais mudanças e influências sobre os estudantes do meio do curso, além do tempo dispensado na resposta do questionário e do temor da exposição dos dados dos participantes, ou certo constrangimento. Para esclarecimento do participante foi utilizado o TCLE, com intuito de garantir sigilo e anonimato, demonstrar relevância do projeto e obter autorização para coleta de dados. Para tal, quem teve dúvidas pôde contatar com as pesquisadoras, que esclareceram e acolheram os participantes, e poderiam encaminhar ao Núcleo de Atenção Psicopedagógica, caso fosse necessário.

Os benefícios relacionaram-se com a aquisição de conhecimento através do uso de dados e resultados apresentados por esse estudo pela instituição como meio de reflexão sobre a influência do currículo formal nos alunos; propiciar uma maior atenção à educação médica da instituição e do curso de uma maneira geral; disponibilizado um estudo à sociedade sobre educação médica brasileira abrangendo principalmente o ciclo básico, pré-clínica; e por fim, promovido uma possível reflexão dos alunos sobre quem são diante da profissão.

\section{Dados quantitativos}

Os questionários foram aplicados e analisados com uma amostra de 197 estudantes. A média de idade dos estudantes foi de 21,86 anos (DP: +/- 2,3), a idade de maior frequência 21 anos e idade mínima de 18 e máxima de 33 anos. Desses, 111 (56,3\%) são do sexo feminino e $86(43,7 \%)$ do sexo masculino. Analisando os semestres correspondentes ao $3^{\circ}$ ano de faculdade, tem-se $99(50,3 \%)$ do $5^{\circ}$ semestre e $98(49,7 \%)$ do $6^{\circ}$ semestre (Tabela 1 ).

Ainda sobre características da população de estudo, tem-se $88(44,7 \%)$ católicos, 16 (8,1\%) evangélicos, 19 $(9,6 \%)$ espírita, $16(8,1 \%)$ agnósticos, $8(4,1 \%)$ ateus, $1(0,5 \%)$ budista e $49(24,9 \%)$ sem religião. Sobre o estado civil dos participantes, tem-se 197 (100\%) que se definiram como solteiro. Em relação à moradia, 130 (69\%) relataram estar morando com os pais, 28 $(14,2 \%)$ sozinhos, $10(5,1 \%)$ com irmão, $12(6,1 \%)$ com amigos, $12(6,1 \%)$ com outros parentes e $5(2,5 \%)$ com namorado (a) (Tabela 1).

Quando analisados os aspectos profissionais e acadêmicos, registram-se 184 (93,4\%) sem formação prévia e $13(6,6 \%)$ com formação prévia. Ao ser questionado sobre ter participado de curso pré-vestibular e por quanto tempo, tem-se uma média de 1,21 anos (DP +/-1,03) com maior frequência para 1 ano de curso pré-vestibular. 0 mínimo em anos foi de 0 e o máximo de 6 anos. No quesito realização de atividades extracurriculares, $181(91,9 \%)$ participam de alguma atividade como liga, monitoria e pesquisa, e $16(8,1 \%)$ não participam de nenhuma atividade. Esses dados são mostrados na Tabela 1. 
Tabela 1. Características demográficas dos estudantes incluídas no estudo

\begin{tabular}{|c|c|c|c|}
\hline Dados dos discentes & & & \\
\hline \multicolumn{4}{|l|}{ Idade (anos) } \\
\hline & Mínimo & \multicolumn{2}{|c|}{18} \\
\hline & Máximo & \multicolumn{2}{|c|}{33} \\
\hline & Média (DP) & \multirow{2}{*}{\multicolumn{2}{|c|}{$\begin{array}{l}21,86+/-2,3 \\
21\end{array}$}} \\
\hline & Moda & & \\
\hline \multicolumn{4}{|l|}{ Pré-vestibular (anos) } \\
\hline & Mínimo & \multicolumn{2}{|c|}{0} \\
\hline & Máximo & \multicolumn{2}{|c|}{6} \\
\hline & Média (DP) & \multicolumn{2}{|c|}{$1,21+/-1,03$} \\
\hline & Moda & \multicolumn{2}{|c|}{1} \\
\hline \multirow[t]{3}{*}{ Sexo } & & $\mathbf{N}$ & $\%$ \\
\hline & Feminino & 111 & 56,3 \\
\hline & Masculino & 86 & 43,7 \\
\hline \multirow[t]{3}{*}{ Semestre } & & $\mathbf{N}$ & $\%$ \\
\hline & $5^{\circ}$ & 99 & 50,3 \\
\hline & $6^{\circ}$ & 98 & 49,7 \\
\hline \multirow[t]{8}{*}{ Religião } & & $\mathbf{N}$ & $\%$ \\
\hline & Católica & 88 & 44,7 \\
\hline & Evangélica & 16 & 8,1 \\
\hline & Espírita & 19 & 9,6 \\
\hline & Agnóstica & 16 & 8,1 \\
\hline & Ateu & 8 & 4,1 \\
\hline & Budista & 1 & 0,5 \\
\hline & Nenhuma & 49 & 24,9 \\
\hline \multirow[t]{2}{*}{ Estado Civil } & & $\mathbf{N}$ & $\%$ \\
\hline & Solteiro & 197 & 100 \\
\hline \multirow[t]{3}{*}{ Formação prévia } & & $\mathbf{N}$ & $\%$ \\
\hline & Sim & 13 & 6,6 \\
\hline & Não & 184 & 93,4 \\
\hline \multirow[t]{7}{*}{ Moradia } & & $\mathbf{N}$ & $\%$ \\
\hline & Pais & 130 & 66 \\
\hline & Sozinho & 28 & 14,2 \\
\hline & Amigos & 12 & 6,1 \\
\hline & Parentes & 12 & 6,1 \\
\hline & Irmão & 10 & 5,1 \\
\hline & Namorado & 5 & 2,5 \\
\hline Extracurricular & & $\mathbf{N}$ & $\%$ \\
\hline \multirow[t]{2}{*}{ Liga/monitoria/pesquisa } & & 181 & 91,9 \\
\hline & Nenhuma & 16 & 8,1 \\
\hline
\end{tabular}

Fonte: As autoras (2020). 
Após a caracterização da população de estudo, o questionário seguiu para o aspecto de vivências no curso e influências antes do início do curso e durante até o terceiro ano. Ao ser questionado sobre a motivação de escolha da medicina, $137(69,4 \%)$ responderam vocação, 96 (47,6\%) desejo de conhecimento, 48 (24,6\%) financeiro, 44 $(22,2 \%)$ não se adequar em outra área, 40 (20,1\%) influência dos pais/família, e 14 (7\%) status social (Gráfico 1).

Gráfico 1. Motivações para a escolha do curso de medicina

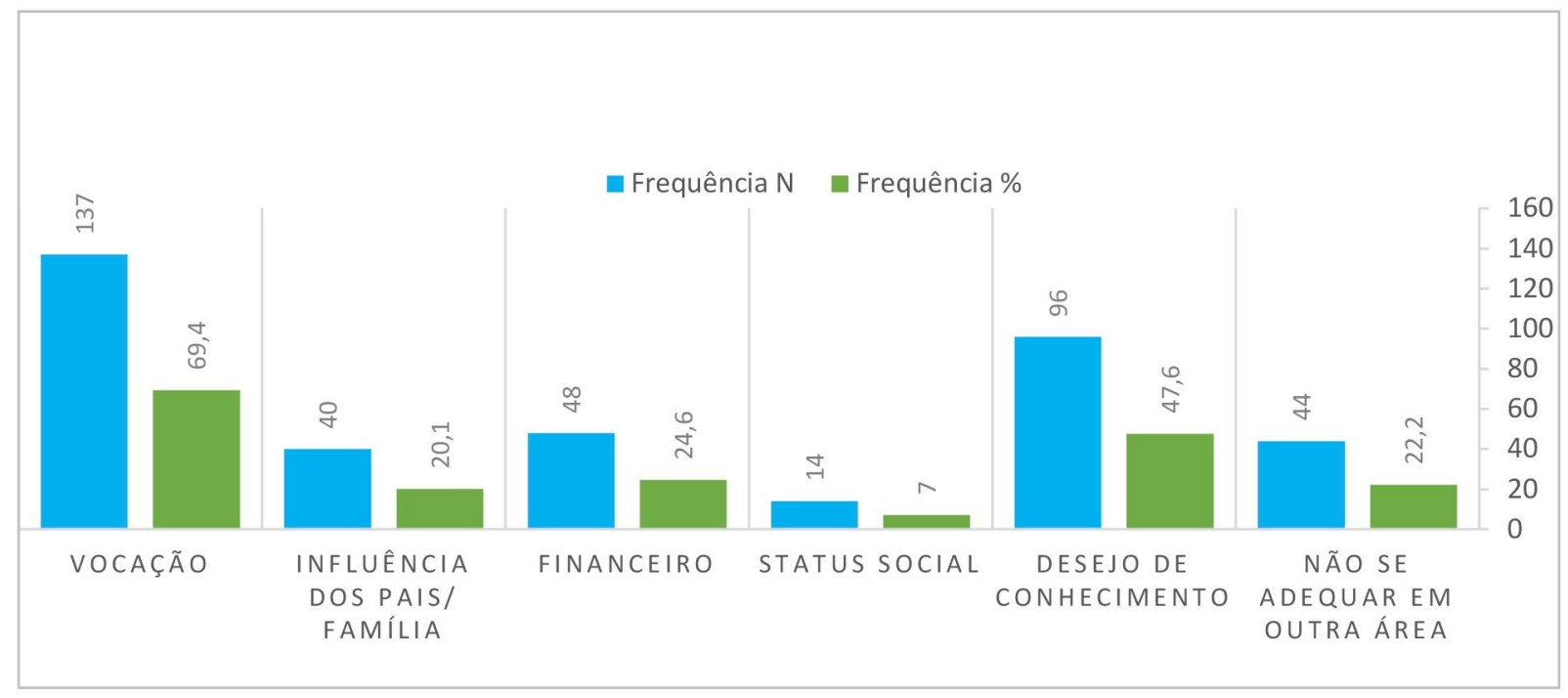

Fonte: As autoras (2020)

Ainda sobre os aspectos das vivências no curso e influências antes do início do curso, a partir do questionamento sobre se houve mudança na maneira de pensar e agir diante do paciente e de questões humanísticas desde a entrada no curso até o momento, 190 (96,4\%) participantes responderam que sim. Apenas $6(3 \%)$ responderam que não e 1 (0,6\%) não respondeu à pergunta (Gráfico 2).

Sobre as expectativas para o significado do curso antes da entrada até o momento atual, perguntou-se se elas foram atendidas. Das respostas, $161(81,7 \%)$ responderam sim, $33(16,8 \%)$ responderam não e $3(1,5 \%)$ não responderam à pergunta (Gráfico 2).

Diante da pergunta se o aluno se sente desmotivado, culpado ou com vergonha quando falha durante a prática clínica, $120(60,9 \%)$ responderam não e $76(38,6 \%)$ responderam sim. Apenas $1(0,5 \%)$ estudante não respondeu à questão (Gráfico 2).

A experiência e influência do professor/médico/mentor na relação médico - paciente também foi avaliada. A influência positiva ou negativa foi percebida por 190 (96,4\%) participantes que responderam sim à pergunta. Uma minoria, 7 (3,6\%) estudantes, responderam não terem sofrido qualquer influência (Gráfico 2).

A matriz curricular de medicina, incluindo práticas ambulatoriais e cirúrgicas foi outro quesito avaliado quando perguntado se os alunos percebem a prática médica pautada no humanismo. Das respostas, 186 (94,4\%) responderam sim e $11(5,6 \%)$ respondendo não (Gráfico 2$)$. 


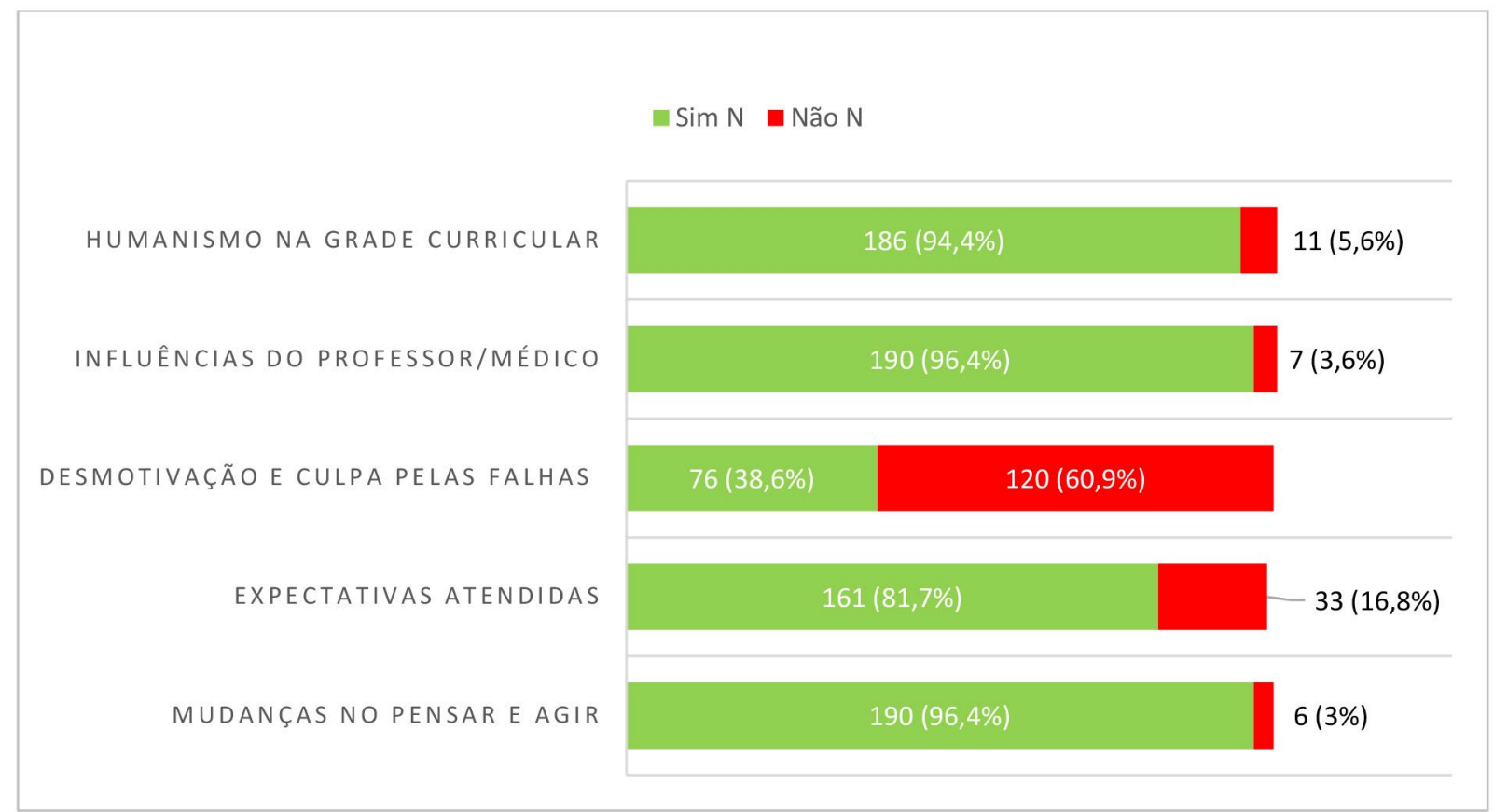

Fonte: As autoras (2020).

Em algumas das perguntas do questionário, as respostas foram graduadas como concordo fortemente, concordo, concordo em parte, discordo e discordo fortemente. Com essa graduação foi possível uma melhor análise da opinião dos alunos,. Dessa forma, foi questionado aos estudantes se concordavam que há competitividade dentro do curso em relação à notas, conhecimento e realização de atividades extracurriculares. Um número de 99 $(50,3 \%)$ concordaram fortemente com a afirmativa, 47 (23,9\%) concordaram e 41 (20,8\%) concordaram em parte. Discordaram da afirmativa apenas 4 (2\%) e 4 (2\%) discordaram fortemente (Gráfico 3).

Gráfico 3. Aspectos do curso e da prática clínica II

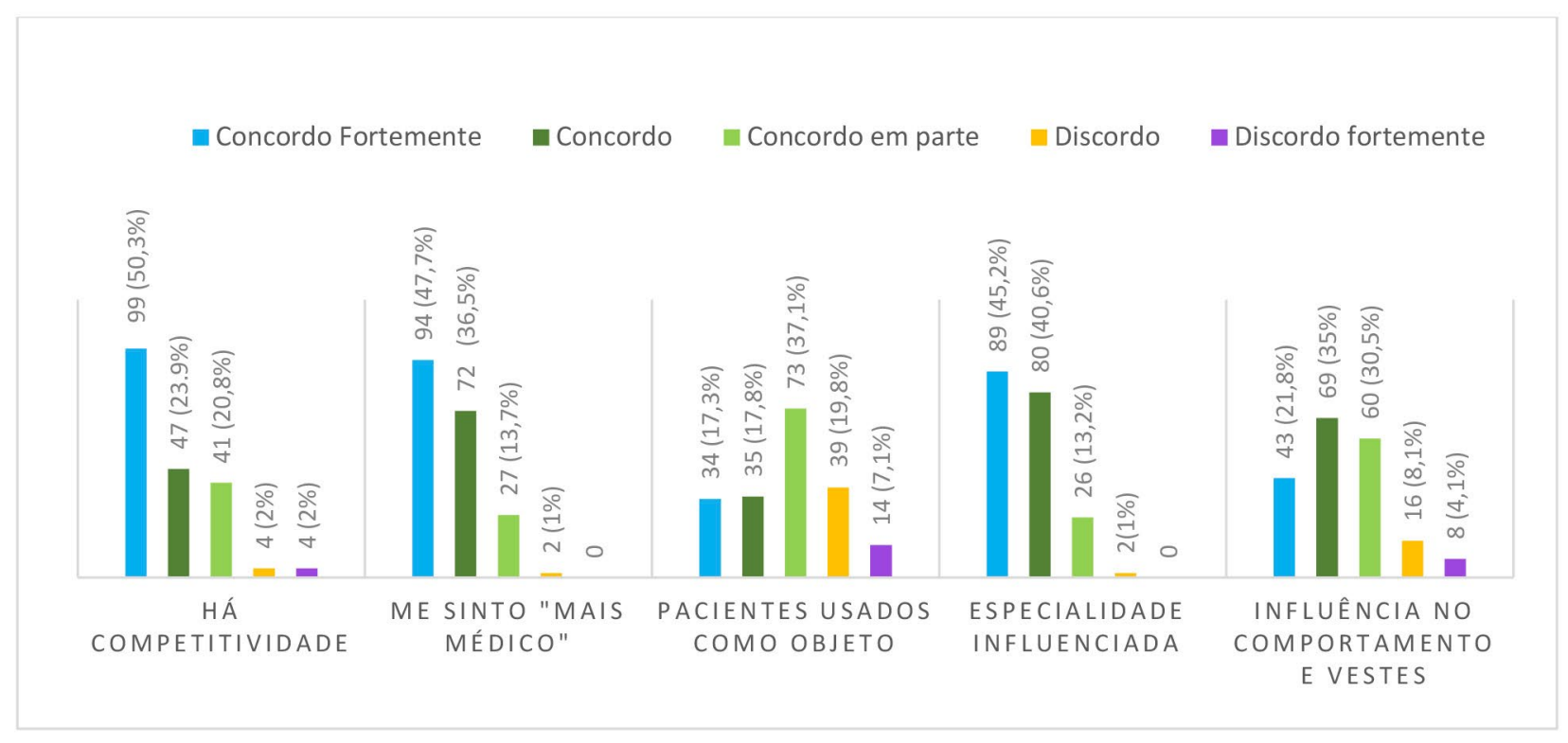

Fonte: As autoras (2020). 
A prática clínica/hospitalar foi abordada com o seguinte questionamento: Sinto que sou "mais médico" após o início das práticas clínicas/ hospitalares do $5^{\circ}$ e $6^{\circ}$ semestre. Responderam concordo fortemente $94(47,7 \%)$ alunos, concordo $72(36,5 \%)$ e concordo em parte $27(13,7 \%)$. Somente $2(1 \%)$ discordaram e não houve resposta na alternativa discordo fortemente (Gráfico 3).

Não obstante, dentro da prática clínica com os pacientes já diagnosticados e internados foi questionado se o estudante sentia que estava usando-os como objeto. Das respostas, $34(17,3 \%)$ concordaram fortemente, $35(17,8 \%)$ concordaram e $73(37,1 \%)$ concordaram em parte. Discordaram do questionamento $39(19,8 \%)$ e discordaram fortemente $14(7,1 \%)$ (Gráfico 3).

No aspecto de influências, também foi analisado se a escolha por uma especialidade pode ser influenciada por um professor/médico/mentor. Concordaram fortemente $89(45,2 \%)$ dos alunos, concordaram 80
$(40,6 \%)$ e concordaram em parte 26 (13,2\%). Nesse quesito, apenas $2(1 \%)$ discordaram e não houve nenhuma resposta para a categoria discordo fortemente (Gráfico 3).

Concomitantemente, $43(21,8 \%)$ dos participantes concordaram fortemente que a faculdade influencia o modo de se comportar e vestir, 69 (35\%) concordaram com a afirmativa e 60 (30,5\%) concordaram em parte. Discordaram da questão $16(8,1 \%)$ participantes e discordaram fortemente $8(4,1 \%)$ (Gráfico 3).

\section{Dados qualitativos}

Os dados qualitativos se basearam em uma proposta de relato do sentimento do estudante no $1^{\circ}, 2^{\circ}$ e $3^{\circ}$ ano a partir das seguintes questões: Minhas expectativas foram atendidas ou me frustrei nesse ano com o curso? Me senti distante de ser de "fato" um médico? Me questionei sobre ter feito a escolha pelo curso? Me senti/ sinto feliz com tudo que fiz no curso até o momento? Como mostra a Figura 1, abaixo.

Figura 1. Sentimentos do estudante
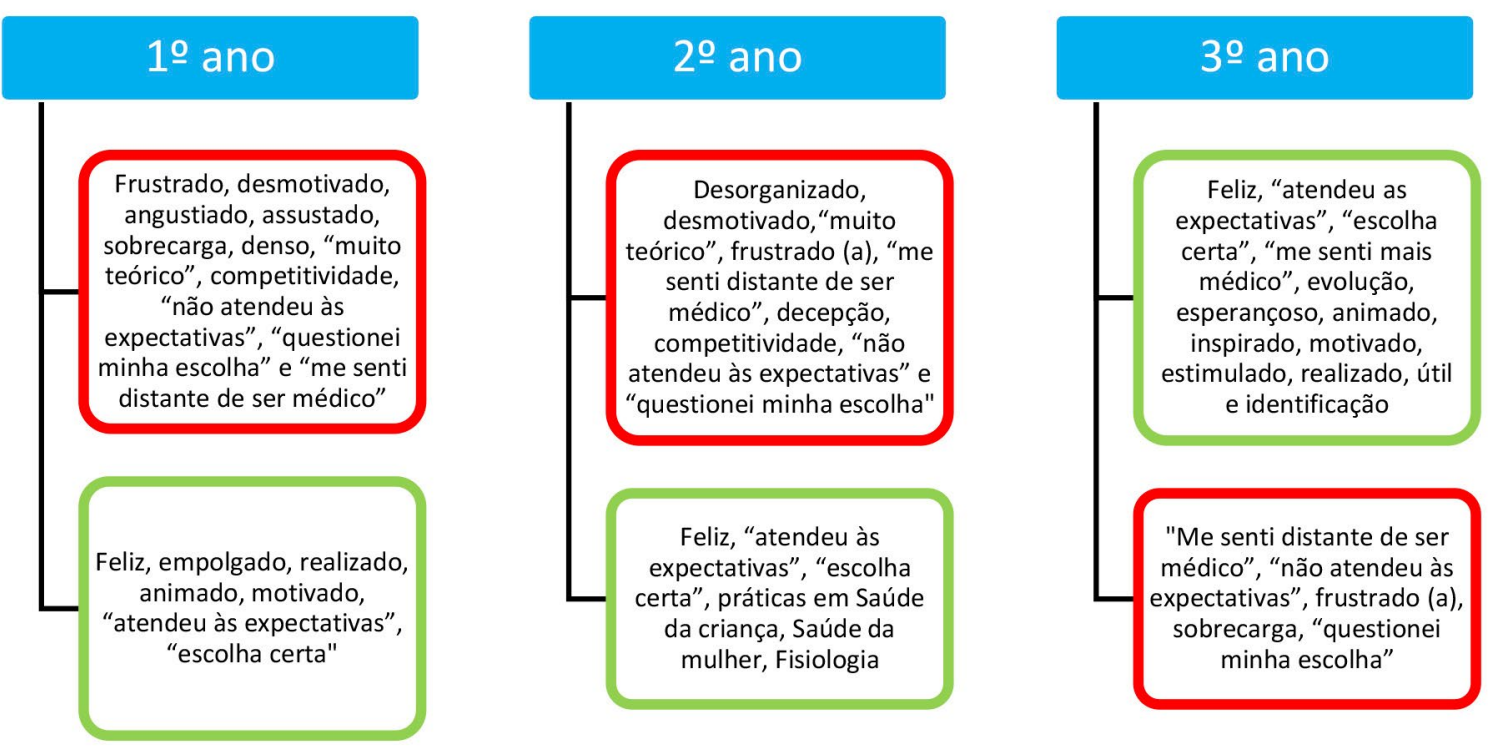

Fonte: As autoras (2020). 
A partir da análise de cada ano foi possível extrair algumas palavras e expressões que tiveram uma maior frequência e formar duas categorias: sentimentos positivos e sentimentos negativos. Nos relatos do primeiro ano de curso, grupo de palavras e expressões com uma conotação negativa foi frequente, dentre as quais estão: frustrado(a), desmotivado(a), angustiado(a), assustado(a), sobrecarga, denso, "muito teórico", competitividade, "não atendeu às expectativas", "questionei minha escolha" e "me senti distante de ser médico". Destas, a palavra frustração e a expressão "me senti distante de ser médico" tem um destaque em relação à repetição.

Ainda no primeiro ano, outras palavras e expressões de conotação positiva também foram vistas: feliz, empolgado, realizado, animado, motivado, "atendeu às expectativas", "escolha certa". De um modo geral, os estudantes atribuíam todas estas à o primeiro momento de ingresso ao curso de medicina. Qualificaram, uma minoria, ainda, o primeiro ano como organizado e como a teoria sendo fundamental para o desenvolvimento no curso.

O segundo ano de curso foi descrito com uma maior frequência de palavras com conotação negativa como: desorganizado, desmotivado(a), "muito teórico", frustrado(a), "me senti distante de ser médico", decepção, competitividade, "não atendeu às expectativas" e "questionei minha escolha".

Caracterizaram de uma forma positiva o segundo ano com as seguintes palavras e expressões: feliz, "atendeu às expectativas", "escolha certa". Estas tiveram uma frequência menor quando comparado às palavras de conotação negativa no mesmo ano e quando comparado às palavras de conotação positiva no primeiro ano.

Não obstante, atribuíram uma melhora nas expectativas no segundo ano pela adaptação ao curso, pela prática nas matérias de Saúde da Criança e Saúde da Mulher no $3^{\circ}$ semestre e Bases da semiologia no $4^{\circ}$ semestre, assim como a matéria Fisiologia. Houve também um destaque para o $3^{\circ}$ semestre em geral, porém com uma conotação negativa.
Para o $3^{\circ}$ ano, os estudantes utilizaram com maior frequência palavras e expressões positivas como: feliz, "atendeu as expectativas", "escolha certa", "me senti mais médico", evolução, esperançoso, animado, inspirado, motivado, estimulado, realizado, útil e identificação. Foi compartilhado pela maioria dos alunos a ideia de que a prática clínica e cirúrgica aproximou-os da identificação como médico, bem como o contato com o paciente. A participação em grupos de pesquisa, monitoria, ligas também foi atribuída como uma forma positiva do ano.

Uma minoria caracterizou o $3^{\circ}$ ano de forma negativa com palavras e expressões como: "me senti distante de ser médico", "não atendeu às expectativas", frustrado (a), sobrecarga, "questionei minha escolha".

Ademais houve uma preocupação com o desenvolvimento do estudante quando este atribuiu ao ano um aumento da responsabilidade e o aparecimento da preocupação com a "proximidade" da residência e término do curso. Relacionaram a responsabilidade e a preocupação à expressão "me senti mais médico".

\section{Discussão}

Diante dos dados quantitativos apresentados nos resultados, é possível traçar um perfil de aluno do $3^{\circ}$ ano. Em sua maioria, apresentam-se com 21 anos, do sexo feminino, católicos, solteiros e que moram com os pais.

No perfil acadêmico, percebe-se que o estudante é caracterizado como sem formação prévia, ter realizado 1 ano de curso pré-vestibular em média e com participação ativa em atividades extracurriculares. A partir disso, é possível inferir que os estudantes entram no curso muito jovens e sem alguma experiência no ambiente de ensino superior. Dessa forma, o estudante sente em seus primeiros anos uma dificuldade na adaptação à medida que a dinâmica do Ensino Superior corresponde a uma maior carga horária e com maior densidade de assuntos ${ }^{1,11}$. 
A entrada no curso foi marcada principalmente pela vocação como motivação seguida do desejo do conhecimento e da influência de pais e família. Estes resultados apontam para o lado humanístico na escolha do curso, indicando também as influências do currículo oculto como o desejo da família e a presença de um familiar exercendo a profissão ${ }^{1,12}$. Blaya (1972), citado por Rocco sobre a questão da escolha médica, afirmou que:

... ser médico sempre foi... uma das escolhas mais estranhas como vocação, pois implica o desejo de estar sempre próximo ao sofrimento e à morte, contingências

tão temidas pelo ser humano (...) é antes de tudo uma curiosidade e um desejo, consciente ou inconsciente, de saber mais e cuidar melhor daquilo que sentimos como doente em nós mesmos. Rocco (1992 apud Ramos, Lima, 2002, p.109)1

A partir do momento do ingresso ao curso, de suas primeiras vivências e de sua adaptação, o estudante percebe em sua grande maioria $(96,4 \%)$, uma mudança na maneira de pensar e agir diante do paciente e de questões humanísticas. O que confirma a descrição de socialização, "o processo pelo qual uma pessoa aprende a funcionar dentro de uma determinada sociedade ou grupo, internalizando seus valores e normas" ${ }^{\prime}$. Sentem que suas expectativas para o curso foram atendidas $(81,7 \%)$, o que sugere a satisfação com o ingresso no curso, com as experiências vividas e como percebem o impacto transformador positivo sobre eles. Embora haja o potencial de conflito entre os valores pessoais e o desenvolvimento de valores profissionais, bem como a dissonância entre as expectativas idealizadas e a realidade da profissão $4,6,13$.

Não obstante, as vivências no decorrer do curso, incluindo as práticas ambulatoriais e cirúrgicas, trouxeram aos estudantes a proximidade com o paciente e sugerem a matriz curricular como pautada no humanismo, já que segundo Mounrouxe (2010) ${ }^{14}$, identidades são construídas e co-construídas em ambientes de interação médica à medida que realizamos nosso trabalho diário; e são desenvolvidas em ambientes relacionais por meio de atividades, e os relacionamentos são componentes centrais da identificação ${ }^{14}$. Corrobora para isto, a opinião dos estudantes quanto a se sentirem mais próximos de ser médico, à medida que a maioria respondeu positivamente à esse questionamento diante da prática clínica ${ }^{14}$.
O professor/mentor também esteve presente como grande influenciador do currículo formal. A relação médico-paciente avaliada pelos alunos nos atendimentos ambulatoriais influenciou-os tanto de maneira positiva a medida que "durante esse processo, os indivíduos podem procurar normas e convenções institucionalizadas, reproduzidas e reforçadas nas interações cotidianas, para estruturar seu comportamento, dando-lhe significado e justificativa"122; quanto negativa, no qual "Os indivíduos são vistos como dando sentido às instituições por meio de suas próprias origens e no contexto atual em que a instituição reside. $O$ significado é criado, e não transmitido, e a cultura é constantemente recriada." Tierney (1997 apud Goldie, 2013, p. 952 $)^{12}$. O que reflete a visão dos alunos diante das experiências próprias nos atendimentos e dos exemplos dados pelos professores/mentores. Além disso, a especialidade do professor/mentor marca a influência dele sobre o currículo formal do aluno, à medida que $100 \%$ responderam que concordavam de alguma forma com a presença desta influência.

Aspectos negativos foram percebidos pelos participantes nas práticas ambulatoriais e cirúrgicas. Diante da pergunta se o aluno se sente desmotivado, culpado ou com vergonha quando falha durante a prática clínica, 120 (60,9\%) responderam não e 76 (38,6\%) responderam sim. Apesar da resposta "não" ter sido mais frequente, chama-se a atenção quando existe uma parcela que respondeu "sim". Por isso, Cruess (2014) afirma que "A socialização é diferente do treinamento." ${ }^{\text {. }}$. E Haffert (apud Cruess et al. 2014) afirmou bem: "embora qualquer treinamento ocupacional envolva o aprendizado de novos conhecimentos e habilidades, é a fusão de conhecimentos e habilidades com um senso de eu alterado que diferencia a socialização do treinamento" $"$. Se os programas educacionais são para ajudar na jornada de transformação de leigo para profissional, o processo de socialização deve ser entendido e tornado o mais favorável e eficaz possível ${ }^{4}$. Simultaneamente, uma grande maioria concorda em algum âmbito com a existência da competitividade no curso, o que pode estar sustentando o questionamento anterior sobre a culpa e a vergonha diante da falha.

As práticas clínicas e cirúrgicas também foram avaliadas como influenciadoras do currículo formal quando a relação-médico paciente é vista pelo aluno de maneira objetificada, em sua grande maioria. 
Concomitantemente, são capazes de influenciar fortemente a maneira de se vestir e de se comportar, o que implica o processo de concepção da identidade profissional como "tornar-se" em vez de "ser" descrito por Scanlon (2011 apud Wong, Trollope-Kumar, 2014, p. 490) ${ }^{15}$. Observar e imitar modelos é um componente essencial na formação da identidade dos profissionais, ratificando os professores como modelos fundamentais para moldar momentos cruciais nessa construção4,2,12,15.

Os dados qualitativos trouxeram o relato dos três primeiros anos da faculdade, caracterizando-os como ciclo básico, e demarcando o terceiro ano como ciclo de transição e ingresso no ciclo clínico-cirúrgico. O primeiro ano do curso foi visto pelos alunos como um momento de felicidade, realização e motivação devido ao ingresso na faculdade, e que atendeu às expectativas. No entanto, foi atribuído ao mesmo um período de frustração, desmotivação e desânimo ao passo que foi referido por eles ser um ano "muito teórico" com pouca prática, com uma densidade de conteúdos grande e sobrecarga devido aos conteúdos e à carga horária. O sentimento que predominou neste ano foi o do distanciamento da medicina e do "ser médico", levando a um discreto questionamento sobre a escolha do curso. Isto pode ser visto nos relatos abaixo:

Participante 19

"As matérias do ciclo básico eram distantes da prática médica, mas me sentia muito feliz e realizada por estar no lugar que desejava, e entender aquele momento como parte necessária do processo".

Participante 7

"Eu me senti um tanto frustrado, principalmente pela grande quantidade de aulas teóricas em relação às práticas e pela distância do que a gente imagina o curso e do que realmente ele é."

Participante 134

"No primeiro ano senti que minhas necessidades foram atendidas, no entanto, eu ainda estava bastante confuso sobre o curso, o que deveria estudar e até onde deveria ler. Dessa forma, me senti distante do auto entendimento da questão de me sentir médico. Cheguei a me questionar diversas vezes sobre a escolha do curso por conta de conflitos internos, porém não via nenhum outro curso em que me identificasse. Alguns momentos não me sentia feliz por conta alta carga e assuntos cobrados, porém na maioria do tempo me sentia muito feliz. "
O segundo ano do curso foi o período caracterizado de uma forma mais negativa que os outros. A frequência da frustração e desmotivação foi maior, mesmo com um grande número de resposta referentes ao ano como atendendo às expectativas. Foi também sinalizado um maior questionamento em relação à escolha do curso e um maior distanciamento do sentimento de "ser médico". O curso continuou sendo pautado em "muito teórico" e o que contrapôs essa característica do sentimento de frustração foram às práticas em Saúde da Criança e Saúde da Mulher no $3^{\circ}$ semestre e o início da Semiologia e a disciplina de Fisiologia no $4^{\circ}$ semestre. Destaca-se também a desorganização dos semestres e em especial o $3^{\circ}$, que foi conotado de uma forma mais negativa pelos estudantes, e a presença de matérias que foram julgadas como pouco producentes ao passo que eles não veem utilidade a curto ou longo prazo. Essa caracterização é vista nos fragmentos de discursos a seguir:

Participante 19

"O conhecimento da fisiologia fez sentido após estudar as matérias do $1^{\circ}$ ano. Saúde da Criança e da Mulher foram muito legais trazendo uma proximidade à prática médica, mas ainda sentia que faltava conteúdo para estar preparada para a prática. Bases da semiologia foi uma matéria muito legal que eu tinha vontade de estudar e aprender mais".

Participante 8

"No $3^{\circ}$ semestre me senti um pouco desmotivada com as matérias e os professores, mas no $4^{\circ}$ semestre senti uma grande melhora nisso e pude me sentir "mais médica" vendo a fisiologia".

Participante 134

"No segundo ano cheguei a me questionar fortemente se realmente queria ser médico, uma vez que é uma profissão que demanda muita responsabilidade e empenho. Me questionei fortemente sobre a minha qualidade de vida, mas decidi seguir em frente".

Participante 135

"Me frustrei completamente nesse ano do curso, me senti muito distante de ser médica e me questionei muito se tinha feito a escolha certa, cogitando inclusive

o abandono/trancamento do curso. Não sentia que estava evoluindo nesse objetivo de me tornar médica, e me sentia burra e infeliz". 
Por fim, o $3^{\circ}$ e último ano analisado nesse estudo foi destacado como positivo. A satisfação dos alunos foi vista na grande frequência de respostas como "feliz", "atendeu às expectativas" escolha certa", "me senti mais médico", evolução, esperançoso, animado, inspirado, motivado, estimulado, realizado, útil e identificação. O que corroborou para esse aspecto positivo foi a transição do ciclo básico para o ciclo clínico, o maior contato com os pacientes e as práticas cirúrgicas. A partir desse momento, o sentimento de "escoIha certa" ganhou um maior destaque assim como a motivação para buscar novos conhecimentos e aplicar a teoria aprendida nos anos anteriores. Os depoimentos aqui ratificam o destaque positivo:

Participante 56

"Me sinto muito feliz com o curso. Esse ano consegui colocar em prática as coisas que aprendi através da prática hospitalar, além de ver de perto todo conteúdo teórico".

Participante 72

"Não me sinto feliz com tudo que fiz. Passei por momentos focados e outros não tanto. Poderia ter aproveitado mais em alguns momentos. No momento, estou satisfeita com meu desempenho e focada $A$ prática incentiva o estudo teórico, porque percebo que serei responsável pela vida/saúde de outra pessoa, por isso me sinto estimulada e preciso saber a teoria.

Gostaria de ter tido essa maturidade mais cedo no curso e mais práticas".

Participante 134 "Estou me sentindo satisfeito com o curso, uma vez que estamos tendo mais contato com pacientes e estamos nos aprofundando na farmacologia. Dessa forma, estou me sentindo mais próximo da prática médica".

Participante 135

"Durante o $5^{\circ}$ semestre me senti um pouco menos frustrada por conta da matéria de Semiologia no hospital, me senti um pouco mais próxima de ser médica e sinto ter feito a escolha certa. Me senti um pouco menos insatisfeita. Já no $6^{\circ}$ semestre, iniciei com uma grande frustração e vontade de abandonar o curso, mas após o início da matéria de Clínica Médica no ambulatório, passei a me sentir completamente satisfeita e abandonei as dúvidas em relação ao curso, me sentindo certa para ser médica, sentindo o conhecimento se consolidar e relacionar, e estou completamente satisfeita".

\section{Limitações e Perspectivas}

As limitações do estudo estiveram presentes desde a seleção da amostra até a análise dos resultados. Durante o processo de seleção, o tempo para aplicação foi limitado e nem todos os estudantes estavam presentes durante esses momentos, por isso não totalizou a quantidade de matriculados regularmente no curso. Além disso, alguns participantes responderam mais de $75 \%$ do questionário, mas não responderam todas as questões. Outra limitação do estudo foram as respostas referentes à última questão, na qual alguns participantes responderam apenas sim ou não e não se justificaram. No entanto, não inviabilizou o estudo e não houve maiores prejuízos. Para que fossem obtidas mais justificativas na última questão, poderia ser realizado um momento específico para aplicação de um novo questionário, com questões mais direcionadas.

\section{Conclusões}

Este estudo teve como objetivo principal investigar o percurso do estudante na formação da identidade profissional desde o curso médio até o momento do meio do curso de medicina.

Dentre as influências que levaram o estudante de medicina a escolher o curso destaca-se a vocação, o desejo do conhecimento e o aspecto financeiro. A família também exerce papel fundamental nessa escolha.

As expectativas antes de iniciar o curso eram positivas e contavam com aulas práticas, organizadas, como ocorriam nos cursos pré-vestibulares. Ao iniciar o curso, os alunos destacam a felicidade do ingresso, mas também a frustração com o distanciamento da prática, e do sentimento de ser médico. A sobrecarga de conteúdo e horários também conotaram de forma negativa as expectativas. No decorrer dos anos, os estudantes começam a compreender o processo de formação da identidade profissional e o tornar-se médico de forma gradual.

Dentro do currículo formal, o que contribui para o processo de formação são as práticas clínicas e cirúrgicas, bem como a influência dos professores e do ciclo básico, que destacam como importante. 
Não obstante, de uma forma geral, os alunos sentem que suas expectativas foram atendidas, mas também sinalizam frustrações durante os anos. A felicidade em fazer e estar no curso não anulam a desmotivação, a decepção e a não identificação com o "ser médico". Assim como também são capazes de destacar com clareza que há competitividade, densidade de conteúdos e uma sobrecarga de tempo e conhecimento. Simultaneamente, entendem que a teoria e o ciclo básico são fundamentais e que sustentam as práticas clínicas e cirúrgicas bem como um olhar crítico sobre a influência de professores/mentores em sua formação. Ademais, acreditam na relação médico-paciente humanizada e percebem que no decorrer dos semestres ampliam o olhar para o cuidado, sustentado desde o princípio pela felicidade, pelas vivências e pelas principais motivações que os levaram a entrar no curso.

\section{Contribuições das autoras}

Ambas as autoras conceberam o estudo, desenharam o método, analisaram os resultados e redigira e aprovaram a versão final.

\section{Conflitos de interesses}

Nenhum conflito financeiro, legal ou político envolvendo terceiros (governo, empresas e fundações privadas, etc.) foi declarado para nenhum aspecto do trabalho submetido (incluindo, mas não se limitando a subvenções e financiamentos, participação em conselho consultivo, desenho de estudo, preparação de manuscrito, análise estatística, etc.).

\section{Referências}

1. Ranos-Cerqueira ATA, Lima MCP. The establishment of the physician's identity: implications for undergraduate medical teaching. Interface - Comunic Saúde Educ. 2002;6(11):107-16. doi: 10.1590/S1414-32832002000200008

2. Jorge Neto $A D$. Professional identity and the humanities at the FAMED/UFU. Rev Bras Educ Med. 2013;37(2):266-274.

3. Frost HD, Regehr G. "I AM a Doctor": Negotiating the discourses of standardization and diversity in professional identity construction. Acad Med. 2013;88(10):1570-7. doi: $10.1097 /$ ACM.0b013e3182a34b05

4. Cruess RL, Cruess SR, Boudreau JD, Snell L, Steinert Y. Reframing medical education to support the development of a professional identity. Acad Med. 2014;89(11):1446-51. doi: 10.1097/ACM.0000000000000427
5. Findyartini A, Sudarsono NC. Remediating lapses in professionalism among undergraduate pre-clinical medical students in an Asian Institution: a multimodal approach. Findyartini and Sudarsono BMC Med Educ. 2018;18(1):88. doi: 10.1186/s12909-018-1206-2

6. Wald HS, White J, Reis SP, Esquibel AY, Anthony D. Grappling with complexity: Medical students' reflective writings about challenging patient encounters as a window into professional identity formation. Med Teach. 2018;41(2):152-160. doi: 10.1080/0142159X.2018.1475727

7. Kay D, Berry A, Coles NA. What Experiences in Medical School Trigger Professional Identity Development?. Teach Learn Med. 2018;31(1):17-25. doi: 10.1080/10401334.2018.1444487

8. Silva LFF, Baracat EC. Medical education - historic perspective and future challenges/ Educação médica - perspectiva histórica e desa os futuros. Rev Med. 2016;95(Special Issue 1):28-36. doi: 10.11606/issn.1679-9836.v95ispe1p28-36

9. Boudreau JD, Fuks A. The Humanities in Medical Education: Ways of Knowing, Doing and Being. J Med Humanit. 2015;36(4):321-36. doi: 10.1007/s10912-014-9285-5

10. Bynum WE, Artino Jr AR. Who Am I, and Who Do I Strive to Be? Applying a Theory of Self-Conscious Emotions to Medical Education. Acad Med. 2018;93(6):874-880. doi: 10.1097/ ACM.0000000000001970

11. Sharpless J, Baldwin N, Cook R, Kofman A, Morley-Fletcher, Slotkin R et al. The Becoming: Students' Reflections on the Process of Professional Identity Formation in Medical Education. Acad Med. 2015;90(6):713-7. doi: 10.1097/ACM.0000000000000729

12. Goldie J. Assessment of professionalism: A consolidation of current thinking. Med Teach. 2013;35(2):e952-6. doi: 10.3109/0142159X.2012.714888

13. Holden MD, Buck E, Luk J, Ambriz F, Boisaubin EV, Clark MA. Professional Identity Formation: Creating a Longitudinal Framework Through TIME (Transformation in Medical Education). Acad Med. 2015;90(6):761-7. doi: 10.1097/ ACM. 0000000000000719

14. Monrouxe LV. Identity, identification and medical education: why should we care?, Med Educ. 2010;44(1):40-9. doi: 10.1111/j.1365-2923.2009.03440.x

15. Wong A, Trollope-Kumar K. Reflections: an inquiry into medical students' professional identity formation. Medi Educ. 2014;48(5):489-501. doi: 10.1111/medu.12382

16. Bardin L. L'Analyse de Contenu. 7.ed. Paris: Presses Universitaires de France, Paris/France; 1993. 